\title{
Exploring a volunteer community residential care facility for new mothers
}

\begin{abstract}
Background:All women deserve a "dwelling space" during their postnatal period after the birth of their infant. This "space" provides her an opportunity to be cared for, to be replenished, to rest and to reflect on herself being a new mother before returning home. We explored a volunteer community residential service set up to help new mothers to document their experiences and determine if the outcomes matched their expectations.

Methods: Semi-structured interviews were offered to all women who had utilised this service since its inception. The questionnaire explored their motivations to seek such as service and to learn of their experiences. The interviews were audio recorded, transcribed and a thematic analysis employed.

Results: Over the last 8 years, 12 women, 4 twice, availed themselves of this service, two being first-time mothers. Reasons given by mothers for utilising this service included recovery from the trauma of childbirth both past and present, physical and emotional, and delaying assuming responsibilities at home. All the women had welcomed the "dwelling space", being mothered, feeling replenished and having time to meaningfully relate to their newborn infant.The ambience of the accommodation and the care they received were above their expectations. All would recommend other new mothers to avail themselves of this service.

Conclusions: This community based residential service more than met the expectations of those who utilised it. Expansion of such services in the wider community, possibly government funded, may be a very cost-effective way to better meet the needs of postnatal care and potentially improve the wellbeing of both mothers and infants.
\end{abstract}

Keywords: postnatal care, residential service, post-partum care, new mothers, neonate
Volume 6 Issue 4 - 2020

\author{
Romina Withanage,' Margaret Hay, ${ }^{2}$ Samuel \\ Menahem ${ }^{3}$ \\ 'Dentistry and Health Sciences University of Melbourne, \\ Australia \\ 2Monash Centre for Professional Development and Monash \\ Online Education, MonashUniversity, Australia \\ ${ }^{3}$ Department of Obstetrics and Gynaecology, Monash University, \\ Australia
}

Correspondence: Samuel Menahem, Department of Paediatrics, University of Melbourne, Royal Children's Hospital, Flemington Road, Parkville Victoria 3052, Australia, Tel +613 9509 I333, Fax +6139576 1352,

Email samuel.menahem@monash.edu

Received: June30, 2020 | Published: July 27, 2020

\section{Introduction}

The postnatal period is a significant transition for women. ${ }^{1}$ The physiological and psychological trauma associated with childbirth may cause mothers to be less able to manage their own well-being and that of their new born infant, potentially perpetuating a lack of confidence in their role as a mother. ${ }^{2,3}$ All women deserve a "dwelling space" in their early days of motherhood. ${ }^{4}$ That "space" may provide a woman a sense of being mothered, to let go, to feel replenished, to rest, and to comfortably evolve into being a mother to her newborn infant prior to her return home - all in the service of supporting their role as a new parent. This dwelling space can become a mother's haven to retreat and contemplate her own well-being.

The challenges of the postpartum period may make it difficult for mothers to actively create a nurturing environment for their newborn and to perceive themselves as "good enough mothers" as described by Winnicott. ${ }^{5}$ Whilst childbirth has many overwhelmingly positive aspects, women in the early postnatal period commonly feel 'drained' emotionally and fatigued from a lack of sleep and the ongoing demands of the new baby. ${ }^{3,6}$ Managing personal care, household chores and adequate sleep were the major challenges that recent mothers experienced during the postpartum period, with the additional challenges of caring for their older children and work-related stress. ${ }^{7}$

During the postnatal period women undergo major hormonal changes as evidenced by a rollercoaster of emotions which may put themselves at risk of mental health problems, further impacted by interrelating factors such as stressful life events, the pregnancy, birthing experiences, parenting experiences and social isolation. ${ }^{8}$ The emotional health of new mothers are also affected by changes in their intimate relationships with their partners, further aggravated by a traumatic childbirth, previous losses in pregnancy etc. ${ }^{8}$ Such experiences highlight the importance of providing new mothers with adequate rest, support, and care, which in turn may help create a better environment for their interaction with the newborn infant which would auger well for the future.

Of all the aspects of perinatal care women state that the postnatal component has the lowest rating. ${ }^{9}, 10$ Their expectations of such care varied depending on whether they were primiparous or multiparous, ${ }^{11}$ with the range of available services not being able to adequately cover their needs. Community-based services are important to the existing health care system as it provides recent mothers with support they require once they are discharged home. However only a limited number of such services that are provided in Australia. Hotel Postnatal Care, Domiciliary Midwife, Maternal Child Health Nurses, Residential Early Parenting Service, Mother Baby units and Mother carers are some of the services that are available for recent mothers after discharge from the hospital. Maternal Child health nurses while concentrating on the infant still play a significant role during the early postnatal period. Residential Early Parenting units and Mother Baby units are provided for mothers that mainly face mental health issues during the early postnatal period.Previous studies have shown gaps in the public provision of community based care, with less than twothirds of mothers accessing public services during the baby's first three months of life. ${ }^{8}$ 
In the light of the above it was enlightening to learn of a complimentary service established by a Jewish grandmother RF to provide domiciliary care for new mothers. In addition, it provided first time mothers and even those who had previous children to have a "dwelling space" as described above. Anecdotal reports suggested that the mothers much appreciated the service provided. This study aimed to review the motivations of those that sought this service, to document their experiences and to determine if the outcomes matched their expectations

\section{Methods}

\section{Residential care facility}

Two self-contained units with private bathrooms were made available for new mothers who in addition had a free run of the house for themselves and other members of their family. Between 1 , not infrequently 2 , and rarely 3 mothers and their infants were accommodated at any 1 time. RF provided all meals and arranged for the rooms to be cleaned, laundry done etc. While breastfeeding was encouraged RF, a non-medical professional, bought in appropriately trained consultants to advise if difficulties arose. Again the service was provided on a complimentary basis.

All women who had utilised this service were contacted by RF. Those who had expressed their willingness to participate, were then sent an email from the lead author to provide information about the planned study and a request for their consent. A questionnaire was developed to provide demographic information prior to a semistructured interview. The latter lasted approximately 30 minutes and sought information about the participant's motivations to utilise the service, their description of the care they received, and to determine if their expectations were met. The interviews were audio recorded and transcribed.

Following Braun and Clarke's ${ }^{12}$ method of qualitative thematic analysis, themes were generated from the interviews. The audio recorded interviews were transcribed, then re-read, coded, and organised into key themes. Data saturation ${ }^{13,14}$ was reached by the eighth interview conducted.The transcribed interview extracts were subjected to an inter-rater reliability test to ensure reliable coding was utilised. Two coders, researcher, and an independent coder, not involved in the study, read three randomly selected transcripts $(25 \%$ of data) and codes assigned. The coders compared and discussed the results. There was $85 \%$ agreement between the coders. Disagreement between the coders were resolved through discussion. Ethical approval for the study was provided by the Medical Education Human Ethics Advisory group, Department of Medical Education, University of Melbourne. Ethic Approval ID 1853236.

\section{Results}

\section{Participants}

A total of twelve women had utilised this service since its establishment eight years ago. All agreed to participate in the study (Table 1). Four out of the twelve women had returned for a second time. A further four expressed their desire to return to the service following their next pregnancy. Nine women who attended this service were confined in public hospitals while three in a private hospital. One had experienced a miscarriage, a second had a sick infant during her stay, while a third mother utilised this service alone as her newborn was diagnosed with congenital cardiac disease and required admission to a tertiary centre. The length of stay in the unit varied between three days and up to two weeks, all being "admitted" following their discharge from hospital. Eight of the women had more than two children at home including one with nine other children.

\section{Reasons for utilizing the service}

All provided similar reasons as to why they sought this service. Three major themes (Table 2) were identified: (a) difficult birthing experiences, (b) responsibilities at home and (c) personal reasons. These factors contributed to them seeking further postnatal support despite having their maximum stay at the respective hospitals which ranged from 1 to 4 days.

\section{Birthing experience}

All twelve women commented on how exhausted they felt once they had gone through childbirth. Initially, most did not consider utilising this service as they were eager to return home. They changed their minds following the stress of their labour.A woman with a prolonged labour remarked, "I was so drained from the labour. That was really hard for me after..." Another complained "After birth you are really tired, and you need to rest up and not just physically but also just emotionally."

Similar comments were made by others who expressed how their tiredness contributed to difficulties in caring for and feeding their infant.Further comments stated that the hospital stay was too short and failed to provide adequate time for recovery from their labour to allow them to better care for their baby. "Now the private system is only about four days and, in the public, its one day or two days. You know, I think... you know, women haven 't changed in the time that they need to recuperate after having a baby. Because it is a traumatic, life changing experience"

\section{Home responsibilities}

Many mothers had older children at home to add to their responsibilities. "So, when you come home you fall into a full-time job beside being a fresh mum for a newborn that needs you around the clock..." Even if the kids are not home which I usually send out the kids to some friends and whatever. I don't have much friends. But still, if you are home you know... You are only gonna load a washing and dig in the cupboards to find something. You only put on something to cook and you know... it's so different."

These comments highlighted the difficulties of having to care for the older children whilst trying to care for their newborn. Two firsttime mothers had little support at home. They had recently moved to Australia and did not have an extended family while their husbands were unable to stay home because of their work commitments.

\section{Personal reasons}

Two mothers sought this service following the recommendation of others. One had experienced postnatal depression previously, and wanted to allow herself time to recover to meet the needs of her newborn. "Like I felt like in order to be able to take care of my family, I need to be able to heal and take care of myself. And just like... to be little bit strong enough to go back home."Three mothers sought this service having had a similar experience overseas, one which required payment, being grateful the service in Melbourne was complimentary. The mother who had had a miscarriage wished to allow herself time away from family, to recover both emotionally and physically as she had required surgery. 
Table I Demographic information of participants

\begin{tabular}{|c|c|c|c|c|c|c|}
\hline Participants & Age & $\begin{array}{l}\text { Socio- } \\
\text { economic } \\
\text { status }\end{array}$ & Highest education level & $\begin{array}{l}\text { Number of } \\
\text { children at home }\end{array}$ & $\begin{array}{l}\text { Pregnancy enter care } \\
\text { unit }\end{array}$ & $\begin{array}{l}\text { Length of } \\
\text { stay }\end{array}$ \\
\hline I & 35 & Home duties & Tertiary studies & 2 & First pregnancy & 2 weeks \\
\hline 2 & 41 & Employed & Tertiary Studies & 6 & Sixth Pregnancy & 4 days \\
\hline 3 & 29 & Home duties & Secondary Education & 3 & Second and third & 2 weeks \\
\hline 4 & 36 & Home duties & Tertiary Studies & 6 & fifth pregnancy & 3 days \\
\hline 5 & 38 & Home duties & Secondary Education & 6 & sixth pregnancy & I week \\
\hline 6 & 32 & Employed & Secondary Education & 5 & Fourth and Fifth & 2 weeks \\
\hline 7 & 43 & Home duties & Tertiary Education & 10 & 9th pregnancy & I week \\
\hline 8 & 25 & Employed & Secondary Education & 2 & First pregnancy & 5 days \\
\hline 9 & 23 & Employed & Secondary Education & 2 & Second pregnancy & I week \\
\hline 10 & 42 & Home duties & Tertiary Education & 9 & 8th and miscarriage & I week \\
\hline II & 24 & Employed & Secondary Education & I & First pregnancy & I week \\
\hline 12 & 29 & Home duties & Secondary Education & 5 & Fifth pregnancy & I week \\
\hline
\end{tabular}

Table 2 Summary of motivations to seek this service

\begin{tabular}{lll}
\hline Key reasons & Subtopics & $\begin{array}{l}\text { Number of } \\
\text { comments } \mathbf{n}=12\end{array}$ \\
\hline Birthing Experience & $\begin{array}{l}\text { Physical Exhaustion after } \\
\text { birth } \\
\text { Short Hospital stays }\end{array}$ & 12 \\
Home environment & $\begin{array}{l}\text { Lack of support at home } \\
\text { Need to care for older }\end{array}$ & 3 \\
Personal reasons & $\begin{array}{l}\text { Recommended by others } \\
\text { prildren at home }\end{array}$ & 3 \\
& $\begin{array}{l}\text { Prior experiences } \\
\text { overseas } \\
\text { Difficulty experiences in } \\
\text { prior pregnancy }\end{array}$ & I \\
\hline
\end{tabular}

\section{Experiences described at the residential care}

The mothers' experiences of the service were explored. The key themes (Table 3) emerging were categorised into (a) time for one's self, (b) freer interactions with baby (c) the care provided for themselves and (d) positive feelings generated of the service provided. These experiences more than met their expectations of the service.

\section{Time for one's self}

The residential stay provided the mothers time to reflect on the physical and emotional changes they had undergone while becoming a mother for their newborn. "You know, you really didn't have to exert any effort there. And just the quiet and relaxation. Just getting oneself time to adjust to this new reality of having a new baby". Mothers also followed the opportunity to rest and sleep. Mothers were grateful for the uninterrupted time available to them whether it was during the night or day. These mothers felt more confident in being up during the night to meet the needs of their newborn, knowing that they will be able to sleep in the next day.

"Three days after the baby you don't sleep at night much. If you don't look after yourself no one does, and it is very easy to flop down..."

The absence of added domestic responsibilities provided these mothers a sense of relief such that they were able relax without the stress of caring for the rest of their family. A mother who had not returned following her second pregnancy provided a comparison of the differences between the two postnatal periods. She stated that her physical recovery after resting fulltime was faster as compared to her next pregnancy. Her ability to breastfeed her first newborn, the comfort she felt and the quantity of milk available was much better as she had time to rest and recover.

\section{Interactions with baby}

The ability to spend quality time with the baby was a common view experienced by all the mothers. They perceived that they were able to better focus on their newborn needs without distractions. "... to have one on one time with the baby before dealing with the others". One mother felt that this time provided her with the opportunity to get into a routine with her baby. One mother who had initial difficulty in settling her baby became increasingly confident in her ability to synchronize to the cues of her baby.

\section{Caring of the mother herself}

The mothers commented positively about the emotional support they had received by the care provider.RF, an experienced grandmother herself, was able to share her experience when asked by the mothers, or alternatively connect them to appropriate professional staff if required. "Just sort of someone... umm ... supporting you and making sure you feel that there is someone for you. Making sure everything is going smoothly..." 
Table 3 Summary of experiences at the service

\begin{tabular}{|c|c|c|}
\hline Key topics & Subtopics & $\begin{array}{l}\text { Number of } \\
\text { comments }\end{array}$ \\
\hline \multirow[t]{3}{*}{ Time for one's self } & Ability to rest and relax & 12 \\
\hline & $\begin{array}{l}\text { Shedding other } \\
\text { responsibilities }\end{array}$ & 8 \\
\hline & Time for sleeping & 3 \\
\hline \multirow[t]{2}{*}{ Interactions with baby } & $\begin{array}{l}\text { Focus on getting to know } \\
\text { the new baby }\end{array}$ & 3 \\
\hline & $\begin{array}{l}\text { Developing a routine with } \\
\text { their baby }\end{array}$ & 3 \\
\hline \multirow[t]{3}{*}{$\begin{array}{l}\text { Personal care of the } \\
\text { new mother }\end{array}$} & $\begin{array}{l}\text { Sense of family created by } \\
\text { the service provider }\end{array}$ & 5 \\
\hline & Beneficial advice and support & 12 \\
\hline & $\begin{array}{l}\text { Guidance in caring of the } \\
\text { baby }\end{array}$ & 3 \\
\hline \multirow[t]{6}{*}{$\begin{array}{l}\text { Positive feelings of the } \\
\text { service provided }\end{array}$} & $\begin{array}{l}\text { Warm and welcoming } \\
\text { environment }\end{array}$ & 6 \\
\hline & $\begin{array}{l}\text { Quiet and relaxing } \\
\text { environment }\end{array}$ & 10 \\
\hline & Culturally appropriate & 12 \\
\hline & Nutritious meals provided & 12 \\
\hline & $\begin{array}{l}\text { Clean and accessible } \\
\text { amenities. }\end{array}$ & 12 \\
\hline & Privacy & 5 \\
\hline
\end{tabular}

"Because she really is there for us and she makes sure that you have everything. She is supportive and she will offer you help in different forms and that's really what mothers need..." Mothers felt they received personalised care by RF tailored to their own needs. The mothers were able to view RF as their "own mother" as they experienced the support she provided.

"I think it was definitely very emotionally wonderful to have a support service. A kind, nurturing person around was wonderful."

\section{Positive feelings of the service}

All expressed their great appreciation. The clean and accessible amenities created a superior "hotel-like" experience for the mothers who felt pampered by RF as they had little other responsibilities whilst with her. Nutritious meals were also provided. "Just to make yourself a salad or eggs for breakfast, you are not going to do that. You are just so exhausted, and you just want to sleep. So, when you are here, she just you know... You don't have to, and you will end up eating healthy meals which you probably wouldn't do at home because you just wouldn't have the energy."

The warm and welcoming nature of RF allowed the mothers to feel comfortable and relaxed. There was a feeling of peacefulness and quietness provided by the surrounding ambience. Mothers were also pleased with the privacy they experienced. "I probably would be comfortable here as this is like a home. Like the fact that it was a home was very nurturing"

Lastly all the mothers, who were Jewish themselves and from the same community felt comfortable in an environment that allowed them to keep the Sabbath and were able to cater to their dietary needs. "It definitely was a big support to have the same cultural understanding of things that make a very big difference"

\section{Discussion}

This study explored a novel postnatal community support service provided for new mothers, apparently one of the only kind in Australia. It highlighted some of the key aspects of the postnatal care that appear to be amiss in our society. All the mothers who utilised the service were generally well. These mothers had uncomplicated pregnancies and were able to care for themselves following discharge from hospital. The care provided for them allowed them to better care their infant. Three out of twelve mothers had utilised the service previously, four said they will use it again and all would recommend it to others. The service had a positive impact on the mothers and aided their recovery during the early postnatal period.

Fatigue and physical exhaustion were common experiences faced by these mothers and extensively reported previously, ${ }^{10,15}$ the hospital stay providing inadequate time to recover. ${ }^{16}$ Such time is needed to recuperate and readjust to the changes their body had undergone. Earlier studies have shown that mothers are unprepared for the physical and emotional experiences of motherhood. ${ }^{15}$ Therefore this service provided all mothers the time to undergo this transition.

The importance of care and support in the early postnatal period were echoed in the experiences of our mothers. The chaotic environments that some mothers find at their home following their hospital discharge may also impact on their well-being and distract them away from the needs of their newborn as observed in other studies where mothers experienced concerns in performing their domestic duties. ${ }^{7}$ Nuclear families lack the practical support that may be provided by members of an extended family. It is recognised that mothers' postpartum mental health is related to both the emotional support and practical help (e.g., housework and childcare activities) provided by the husband and others. Mother carers ${ }^{18,19}$ are an alternative option offered in South Australia to support mothers once discharged home ${ }^{17}$ which may allow mother time for herself to engage in the task of motherhood. Mother carers alleviate household responsibilities from the new mum. This model of care provided by mother carers was positively received though it was unclear how that practice may be further adapted to the wider community.

Emotional support, general encouragement and reassurance on becoming a new mother appears in short supply in the limited time available post-partum within hospitals. ${ }^{20}$ Such reassurance is important to improve a mother's confidence and her ability to cope with the needs of their newborn. ${ }^{21}$ The nurturing and home-like environment that RF provided appeared to enhance the mothers' ability to assume their motherhood role with renewed confidence. Occurring within an appropriate cultural setting further aided this process. Postnatal support services that are more aligned to the mothers' cultural and religious practices allows them to be more comfortable within the environment they find themselves in.

Of further importance the mothers commented not only on their faster physical recovery, but also felt more comfortable with breast feeding with an improved supply. The reduction in the mothers' anxiety enhanced the breast feeding. Overcoming the sense of being "overwhelmed" and improving the psychological well-being of the mothers may well reduce or prevent post-partum depression.

In the Australian culture, postnatal care is based on the assumption 
that women need little care after discharge from home. ${ }^{22}$ Yet multiple challenges occur during their transition home.Community based services are important to the existing health care system as it provides new mothers with support they require once they are discharged home. Many of the existing residential postnatal centres focus on mothers that have major problems during their postnatal period Mother Baby Units ${ }^{23}$ and the Early Parenting Centres ${ }^{24}$ are services offered to women that have either a psychotic illness or substantial psychological distress. Yet the majority of well mothers such as the ones that had accessed this service, are generally not well catered for in their early postnatal period.

\section{Limitations}

This study reported on a small number of mothers that utilized a service catering to a segment of one community. The findings may not therefore be generalised and may not be applicable to other women from different groups, or to the general community at large. Secondly there was no comparative group of mothers who went straight home after discharge. Finally, mothers of this study may have felt obligated to provide a positive view of the service because of its complimentary nature making light of any negative aspects.

\section{Conclusion}

Women rate postnatal care as the least well provided aspect of their perinatal care. Many seem unprepared for the physical and emotional demands of motherhood. This community based residential postnatal service more than met the expectations of those who utilised it, provided the postnatal support required and appeared to be a costeffective means of providing much appreciated additional care for the new mothers. Expansion of such a service into the wider community, possibly government funded, may be able to provide further benefits for the "good-enough" mothers from different communities. In addition follow-up of those utilising such services may show better health outcomes and improved well-being both for the mothers and infants which would auger well for the future. Such outcomes may well reduce the call on the need for subsequent medical services.

\section{Acknowledgments}

Appreciation is expressed to Mrs Raizel Fogel for allowing us to study this relatively unique service and for being so helpful in enlisting the co-operation of the participants involved. The mothers are thanked for allowing themselves to be interviewed. Dr Justin Bilszta assisted in obtaining Ethics approval.

\section{Conflicts of interest}

Author declare that there is no conflict of interest.

\section{Funding}

None.

\section{References}

1. Forster DA, McLachlan HL, Rayner J, et al. The early postnatal period: exploring women's views, expectations and experiences of care using focus groups in Victoria, Australia. BMC Pregnancy Childbirth. 2008;8:27.

2. Priddis H, Thornton C, Fowler C, et al. Characteristics and service needs of women and babies admitted to residential parenting units in New South Wales: A mixed-methods study. Journal of Clinical Nursing. 2018;27(15-16):2963-2973.

3. Lesley B, Louise E, Frances R, et al. Becoming a mother-an analysis of women's experience of early motherhood. Journal of Advanced Nursing. 1997;25(4):719-728.

4. Smythe E, Payne D, Wilson S, et al. The dwelling space of postnatal care. Women and Birth. 2013;26(2):110-113.

5. Winnicott DW. The theory of the parent-infant relationship. The International Journal of Psychoanalysis. 1960;41:585-595.

6. Kurth E, Krahenbuhl K, Eicher M, et al. Safe start at home: what parents of newborns need after early discharge from hospital - a focus group study. BMC Health Serv Res. 2016;6(82):82.

7. Negron R, Martin A, Almog M, et al. Social support during the postpartum period: mothers' views on needs, expectations, and mobilization of support. Maternal Child Health J. 2013;17(4):616-623.

8. Biggs LJ, McLachlan HL, Shafiei T, et al. 'I need help': Reasons new and re-engaging callers contact the PANDA-Perinatal Anxiety and Depression Australia National Helpline. Health \& Social Care in the Community. 2019;27(3):717-728.

9. Brown SJ, Davey M-A, Bruinsma FJ. Women's views and experiences of postnatal hospital care in the Victorian Survey of Recent Mothers 2000. Midwifery. 2005;21(2):109-126.

10. Rayner J, McLachlan Helen L, Forster Della A, et al. The early postnatal period: Exploring women's views, expectations and experiences of care using focus groups in Victoria, Australia. BMC Pregnancy and Childbirth. 2008;8(1):27.

11. McLachlan HL, Gold L, Forster DA, et al. Women's views of postnatal care in the context of the increasing pressure on postnatal beds in Australia. Women Birth. 2009;22(4):128-133.

12. Braun V, Clarke V. Using thematic analysis in psychology. Qualitative Research in Psychology. 2006;3(2):77-101.

13. Fusch PI, Ness LR. Are we there yet? Data saturation in qualitative research. The Qualitative Report. 2015;20(9):1408-1416.

14. O Reilly M, Parker N. Unsatisfactory Saturation': a critical exploration of the notion of saturated samples sizes in qualitative research. Qualitative Research. 2013;13(2):190-197.

15. Barnes M, Pratt J, Finlayson K, et al. Learning about baby: what new mothers would like to know. J Perinat Educ. 2008;17(3):33-41.

16. McLachlan HL, Forster DA, Yelland J, et al. Is the organisation and structure of hospital postnatal care a barrier to quality care? Findings from a state-wide review in Victoria, Australia. Midwifery. 2008;24(3):358-370.

17. Xie R-H, Yang J, Liao S, et al. Prenatal family support, postnatal family support and postpartum depression. The Australian and New Zealand Journal of Obstetrics and Gynaecology. 2010;50(4):340-345.

18. Zadoroznyi M, Sutherland J. A New Postnatal Home Care Worker: Challenges for Training, Implementation and Policy. Australian Journal of Social Issues. 2007;42(2):227-240.

19. Zadoroznyj M. Postnatal care in the community: Report of an evaluation of birthing women's assessments of a postnatal home-care programme. Health and Social Care in the Community. 2007;15(1):35-44.

20. Woodward BM, Zadoroznyj M, Benoit C. Beyond birth: Women's concerns about post-birth care in an Australian urban community. Women and Birth. 2016;29(2):153-159. 
21. Barnes M, Pratt J, Finlayson K, et al. Continuing Education Module Learning About Baby: What New Mothers Would Like to Know. The Journal of Perinatal Education. 2008;17(3):33-41.

22. Zadoroznyj M, Benoit C, Berry S. Motherhood, Medicine \& Markets: The Changing Cultural Politics of Postnatal Care Provision. Sociological Research Online. 2012;17(3):1-11.
23. Connellan K, Bartholomaeus C, Due C, et al. A systematic review of research on psychiatric mother-baby units. Arch Women Ment Health. 2017;20(3):373-388.

24. Rowe HJ, Fisher JR. The contribution of Australian residential early parenting centres to comprehensive mental health care for mothers of infants: evidence from a prospective study. Int J Ment Health Syst. 2010;4:6 